\title{
Single-neuron Control Strategy of Engineering Mechanical Arm Hydraulic Drive System
}

\author{
LIU Zhong ${ }^{1,2, a}$ YANG Neng ${ }^{2, b}$ and GAO Zhan-Wei ${ }^{2, c}$ \\ ${ }^{1}$ Changshu Institute of Technology ( School of Mechanical Engineering, Changshu, Jiangsu, \\ China, 215500) \\ ${ }^{2}$ Soochow University (School of Mechanical Engineering, Suzhou, Jiangsu, China, 215502) \\ a liuzhong678@sina.com,byangnengde@163.com , c1551593443@qq.com
}

Keywords: Mechanical arm, Hydraulic drive system, PID, Single-neuron, Control

\begin{abstract}
The working environment of engineering mechanical arm hydraulic drive system is complex. The response indicators of the hydraulic drive system need a higher requirement. The conventional PID control method is limited to the complexity and imprecision of the mathematical model of the hydraulic drive system, which leads to the classical parameter tuning method adaptability bad or poor performance in the actual production. This paper puts forward a position control hydraulic cylinder system based on a high-speed on/off valve pilot control. ${ }^{[1]}$ Using a singleneuron control strategy, the single-neuron algorithm is used for the parameter optimization of mechanical arm hydraulic drive system controller. By using AMESim and Matlab co-simulation, it has verified that the single neuron PID control method has a good self-adaptability, robustness and position control response characteristics in variable load applications.
\end{abstract}

\section{The Basic Structure of the Mechanical Arm Hydraulic Drive System}

Hydraulic mechanical arm and hydraulic drive system has been widely used in the field of construction, metallurgical and mining, transportation and military projects, such as smart dismantling machinery, aerial vehicles, hydraulic rock drill vehicle and engineering mechanical arm. It is a nonlinear and uncertain complex system of electro-hydraulic coupling, and the drive control of this system is difficult and complex. For this reason, this paper puts forward a new hydraulic drive system for the mechanical arm. In other words, a hydraulic cylinder electro-hydraulic position control system is composed of cartridge valves pilot controlled by high-speed on/off valves. It can be used for the occasions of high flow (power) and where needs to achieve automatic control and it has many advantages, such as a fast response time, high flow rate, good stability, ease for digital control, etc. As is shown in Fig. 1.

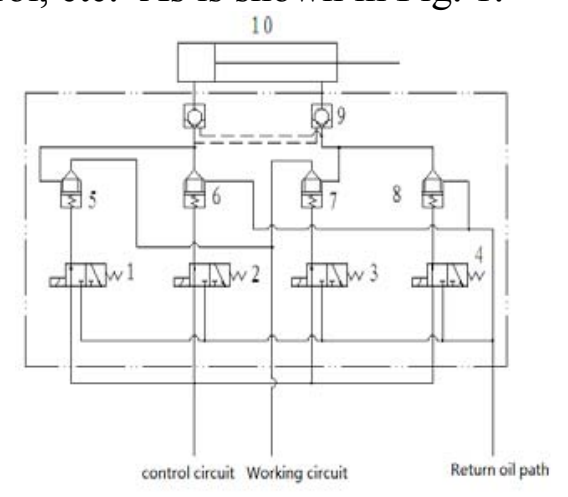

1-4 high-speed on/off valves

5-8 Cartridge cone valve

9 Hydraulic lock

10 Hydraulic cylinder

Fig. 1 New hydraulic position drive system

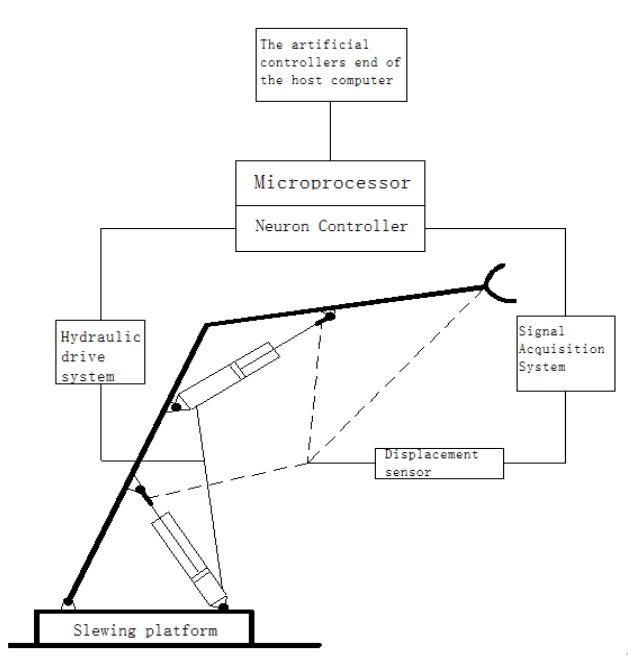

Fig. 2 The schematics of mechanical arm hydraulic drive system control 
As is shown in Fig. 2, the entire system is a hydraulic integrated system, consisting of three parts of the mechanical, electrical and fluid. System completes the changes in oil pressure and flow by Motor and drives circuit to control the oil pumps and valves. This system reflects its electrohydraulic control ideas. This system turns the linear motion of the cylinder into the luffing movement of the mechanical arm. The change torque of the mechanical arm and the information of execution point location are fed back to the electric control part to achieve the closed-loop control. The control section is composed of the data acquisition module, driver amplifier module, the microprocessor module and human-computer exchange module. Human-computer interaction is served by the industrial control computer and the control section is served by the microprocessor module. Single-neuron control algorithm is written in the software and the software package in the microcontroller chip of microprocessor module. The effect of the driver amplifier module is to amplify the PWM signal sent to the high-speed on/off valve which is in the hydraulic drive module. Thus it can achieve precise control of the entire system. ${ }^{[2]}$

\section{Single-neuron PID control strategy for Hydraulic drive system}

The working environment of engineering mechanical arm hydraulic drive system is complex. The response indicators of the hydraulic drive system need a higher requirement. The Conventional PID control method is limited by the complexity and imprecision of the mathematical model of the hydraulic drive system, which leads to the classical parameter tuning method adaptability bad or poor performance in the actual production. In this paper, the single-neuron algorithm is used for the parameter optimization of mechanical arm hydraulic drive system controller based on AMESim and MATLAB / Simulink. The incremental expression of the PID controller is:

$$
\Delta \mathrm{u}(\mathrm{k})=\mathrm{k}_{\mathrm{p}}\left((\mathrm{e}(\mathrm{k})-\mathrm{e}(\mathrm{k}-1))+\mathrm{k}_{\mathrm{i}} \mathrm{e}(\mathrm{k})+\mathrm{k}_{\mathrm{d}}(\mathrm{e}(\mathrm{k})-2 \mathrm{e}(\mathrm{k}-1)+\mathrm{e}(\mathrm{k}-2))\right.
$$

Combining single-neuron and PID controller, we can get the single-neuron PID controller. The controller uses the improved single-neuron adaptive PID control by adjusting the weighting coefficients in order to achieve self-learning and adaptive function. The controller structure is shown in Fig 3.

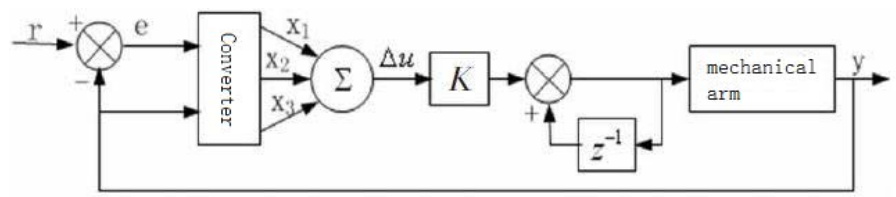

Fig. 3 Single neuron adaptive PID control structure

According to the corresponding papers, it suggests that the online learning correction of PID Parameters is mainly related to $\mathrm{e}(\mathrm{k})$ and $\Delta \mathrm{e}(\mathrm{k})$. Based on this, the section of weighting coefficient in single neuron PID control algorithm can be modified. Among them, $\eta p$ is the learning efficiency of Proportion, $\eta \mathrm{i}$ is the learning efficiency of differentiation and $\eta \mathrm{d}$ is the learning efficiency of integration. We can choose the 3 weight variables as the system state variables. The rules of weights are:

$$
\left\{\begin{array}{l}
w_{1}(k)=w_{1}(k-1)+\eta_{p} e(k) u(k)[e(k)-\Delta e(k)] \\
w_{2}(k)=w_{2}(k-1)+\eta_{i} e(k) u(k)[e(k)-\Delta e(k)] \\
w_{3}(k)=w_{3}(k-1)+\eta_{d} e(k) u(k)[e(k)-\Delta e(k)]
\end{array}\right.
$$

In this case, the control rate shall be:

$$
\mathrm{u}(\mathrm{k})=\mathrm{u}(\mathrm{k}-1)+\mathrm{k} \sum_{\mathrm{i}=1}^{3} \mathrm{w}_{\mathrm{i}}^{0}(\mathrm{k}) \mathrm{x}_{\mathrm{i}}(\mathrm{k})
$$


Normalized weights: $\mathrm{w}_{\mathrm{i}}^{0}(\mathrm{k})=\mathrm{u}(\mathrm{k}-1) / \sum_{\mathrm{i}=1}^{3}\left|\mathrm{w}_{\mathrm{i}}(\mathrm{k})\right|$.To sum up, we can use Matlab to write single neuron PID controller. The core algorithm is written S-function. Packaging the single neuron PID controller constitutes a control module.

After writing S-function, we can create a Simulink model. The steps are: 1) Input the variable name of the function and the variable name of parameter. Click on the S-function module of the nonlinear part in Simulink model library. Input function variable name $\mathrm{T}$, deltaK and $\mathrm{kAlg}$ in accordance with relevant tips; 2) Create subsystem; 3) Mask subsystem. As is shown in fig 4.

The running effect of the single-neuron adaptive PID controller learning algorithm has a big relationship with the selection of adjustable parameters $\eta p$, $\eta \mathrm{i}$, $\eta \mathrm{d}$, K. By a large number of instances of simulation and real control results, we can summarize the following adjustment law:

1) The choice of initial weighting coefficients w1 (0) w2 (0), w3 (0) is based on experience. Its value should be different depending on the controlled different object. Its weight respectively corresponding to the integral coefficient, proportional coefficient and derivative coefficient of PID control, which can refer to the value.

2) The choice of gain $K$ value: $K$ value partial generally causes system response overshoot partial bigger, and $\mathrm{K}$ value partial smaller, which causes the transition process partial longer. Therefore, we can determine a gain $\mathrm{K}$ at first and adjust the gain $\mathrm{k}$ according to the simulation results. In addition, when the delay of the controlled object increasing, the value of $\mathrm{K}$ must be reduced in order to avoid system oscillations.

3) The choice of learning rate $\eta p$, $\eta \mathrm{i}, \eta \mathrm{d}$ : The choice of $\mathrm{K}$ must be reasonable, so that the process overshoot is not too large. If after the value of $\mathrm{K}$ set, the adjustment time of curve will be too long, we can increase $\eta p$ and $\eta i$; if the value of overshoot decreased rapidly below than a given value and the curve oscillation partial big lead to the rise time partial long, we can decrease $\eta p$ to enhance the role of the integral term. These three parameters have a certain margin, so it has a good control effect within a certain range. ${ }^{[3]}$

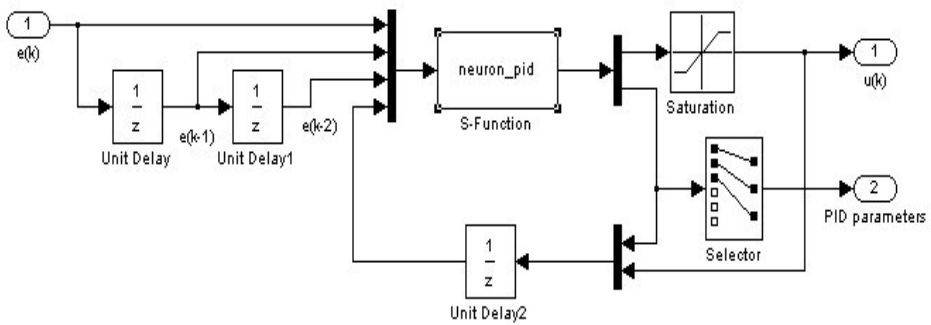

Fig. 4 Single-neuron PID mask subsystem

\section{Establishment of the Co-simulation interface in Matlab and AMESim}

AMESim, as a platform of multidisciplinary field of system simulation, provides interfaces with other software. Using the interface technology of AMESim to Simulink, on the one hand, it can play the AMESim prominent simulation performance of hydraulic module library. On the other hand, it is able to write a single-neuron control algorithm with the powerful MATLAB numerical processing capabilities. The combinations of them can achieve a more perfect complementary effect. This co-simulation technology for multidisciplinary systems can easily create a variety of model. It can change simulation parameters and system control strategy and can solve the problems in simulation technology effectively. For example, the experimental simulation of fluid power transmission and intelligent control.

In order to achieve the co-simulation of two software, we need to install the Visual $\mathrm{C}++$ AMESim and Matlab with Simulink function under the Windows XP and above operating system. The co-simulation interfaces settings are as follows:

1) Copy the VC++ installation folder "vcvars32.bat" to the AMESim installation folder contents.

2) Set the MATLAB environment variable. Set the variables of Matlab installation path in the 
environment variable settings dialog box. It must be noted that software installation path does not allow Chinese and spaces, for these two characters not be recognized by AMESim.

3) Set the system variable PATH and defined it as Windows installation directory.

4) Add software interfaces file directory to the Matlab directory list. The interface file in the installation directory in some versions and the 7.0 version is in the scripting folder.

5) The license file of Co-Simulation is added to the licensing folder of AMESim installation directory.

6) The choice of the compiler. In the premise of the completion of the steps (1), the change method of AMESim compiler is to select the VC compiler in the sub-menu under the menu option. The specific operation of Matlab is: enter the Mex-setup in the Matlab command window to change the compiler. The co-simulation of AMESim and Simulink is to create interface icons which connected with the S-function in Simulink by menu interface in AMESim. The icon only can be inserted when the license file of joint interface existed before. The concrete realization process is generated S-function after system compiler and parameter set in AMESim. In the Simulink environment, treating the completed AMESim model as an ordinary S-function, which can become a part of the Simulink model of the system. The $\mathrm{S}$ function must be defined with AMESim model name plus the form of "_, for data exchange between the two softwares. The parameters setting in S-function is the output format of the simulation results, standing for whether to generate the result of files and whether to set the acquisition time interval.

\section{The co-simulation and analysis}

The mechanical arm hydraulic drive system is nonlinear and its load is uncertain. The domestic scholars have some research and analysis about the control method of mechanical arm, such as active disturbance rejection control, the mechanical arm PID control based on the PSO algorithm, robust control, nerve synovial control, etc. These control methods have their own advantages and disadvantages. Some control effect is not satisfactory, and some control principle is too cumbersome or additional assumptions are more. This is not conducive to the engineering application and the promotion of method.

In this paper, based on the combination of the improved algorithm of the neural network and PID conventional control methods, we build single-neuron PID adaptive control strategy. Using the advantages of a neural network with self-learning, self-organization, associative memory and parallel processing function and the advantages of the satisfactory of the complex system controlling meet the control requirements of mechanical arm drive. ${ }^{[4]}$

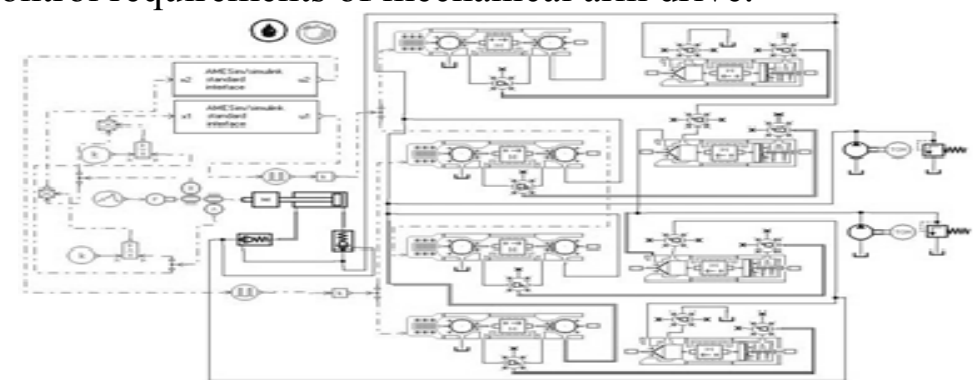

Fig. 5 the co-simulation model of mechanical arm hydraulic drive system under AMESim

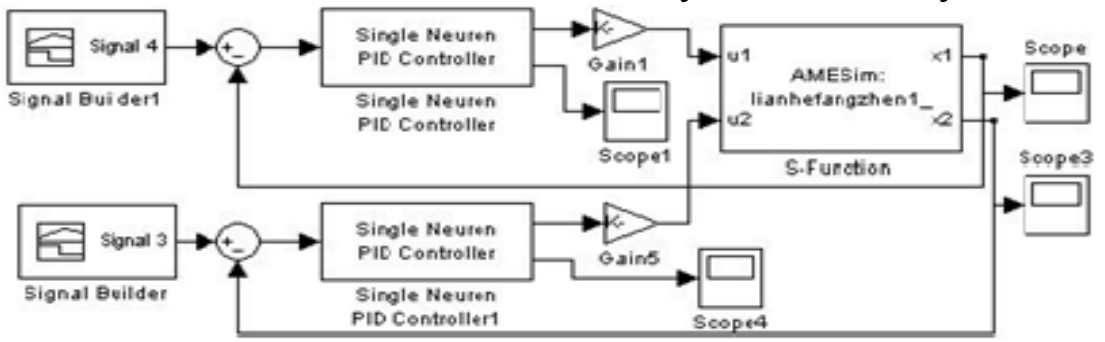

Fig. 6 The co-simulation model of mechanical arm hydraulic drive system under Matlab/Simulink

Fig. 5 shows the with single neuron control algorithm of the manipulator hydraulic driving system in AMESim simulation model. Illustrated two AMESim / Simulink block module for 
software data exchange interface, the essence is the MATLAB / Simulink under the AMESim software package submodule, the model need to build in Matlab interface. As shown in Fig. 6.The single-neuron PID Controller submodel is single-neuron PID package program. AMESim: lianhefangzhen1 submodel is AMESim electro-hydraulic system package model. The input displacement signal is given by Matlab. The input signal of high-speed on/off valves which is after the single neuron PID control strategy and PWM modulation tuning is given by AMESim / Simulink software interface. Thus reflect the control idea of control block diagram shown in Fig. 2. Due to the hydraulic system is relatively complicated and two kinds of software data exchange relatively slow, we can set the simulation parameters of position drive system of hydraulic cylinder piston process and return.

Fig. 7 shows the changing load of cylinder, which (a) for the process (b) for the return load change. Fig. 8 and 9 shows the experimental simulation curve of the process of hydraulic cylinders, which (a) for the PID control (b) for the single neuron PID control. The start time of process stage is set as $0.5 \mathrm{~s}$. The oscillation of error control signal after PWM modulation is larger. The burr phenomenon is coming out when the load mutation time point is $1 \mathrm{~s}$ and $2 \mathrm{~s}$ and its control effect is obviously lower than the single neuron control. The displacement response slightly faster $0.4 \mathrm{~s}$ under single neuron control strategy by observes the displacement curve.

Fig. 10 and 11 are a simulation curve of return stage, which (a) for the PID control (b) for the single neuron PID control, return from 1 s to start. It is not difficult to find that single-neuron PID control PWM modulation curve is obviously better than the ordinary PID control from the curve. The oscillation amplitude of the modulation is small. It is better to follow the change of the cylinder displacement error. The curve of single-neuron control displacement response is close to linear changes, and response time reduced by about $0.2 \mathrm{~s}$, compared with ordinary PID control.

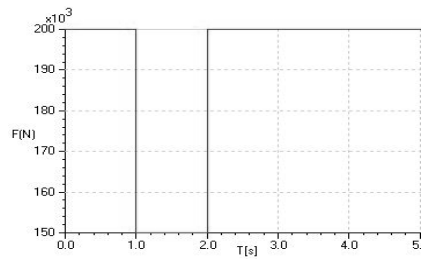

(a)

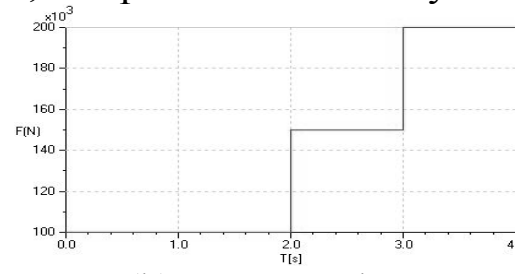

(b) return stroke

Fig. 7 The curve of hydraulic cylinder varying load

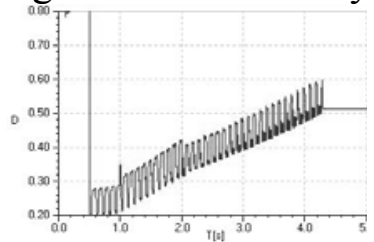

(a) PID control

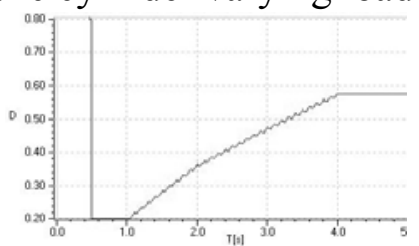

(b) Single neuron PID control

Fig. 8 PWM modulation curve of Process of hydraulic cylinder piston phase error signal

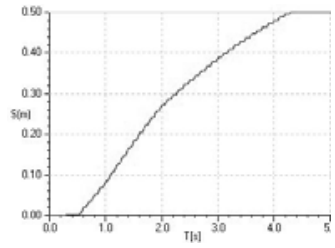

(a) PID control

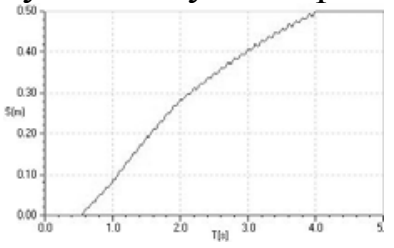

(b) Single neuron PID control

Fig. 9 The curve of Process of hydraulic cylinder piston displacement

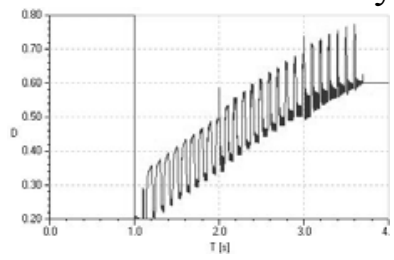

(a) PID control

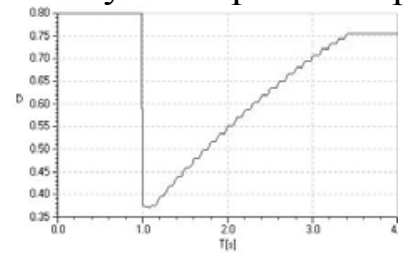

(b) Single neuron PID control

Fig. 10 PWM modulation curve of return stage of hydraulic cylinder piston phase error signal 


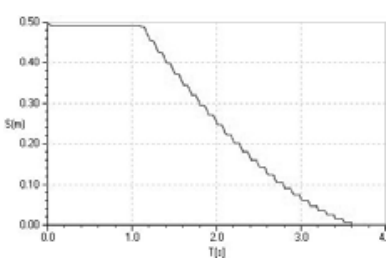

(a) PID control

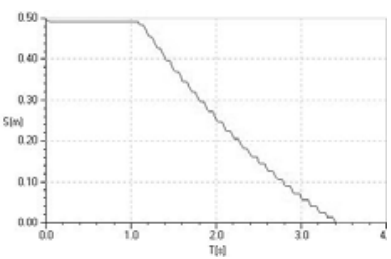

(b) Single neuron PID control

Fig. 11 The curve of return stage of hydraulic cylinder piston displacement

Through the simulation analysis, it is not difficult to find that PWM control thought have fibrillation impact on the action of the actuator. That is to say, the input flow of the executive hydraulic cylinder is corrugated. The drive corrugated of ordinary PID control is particularly apparent. The duty cycle of the control signal has large change amplitude along with the displacement error. The hydraulic system of engineering equipment is insensitive to changes in such flow ripple, but the existence of pressure shock wave has erosion to hydraulic components and oil seals. The single-neuron PID control strategy just solves this problem. The duty cycle of the control signal has smooth change amplitude along with the displacement error and it meets the technical requirements of engineering mechanical arm drive system. However, the complexity of the hydraulic system modeling and the certain limitations of software interfaces lead to the slowness in exchange process of two software data. It affects the tuning efficiency of single-neuron PID parameter and its control effect is not optimized to the best. It validates the adaptivity, robustness and location of the control response of the single neuron PID in varying load conditions by the cosimulation of AMESim and Matlab.

\section{Conclusion}

This paper proposed engineering mechanical arm hydraulic drive system solutions based on the pilot control. At the same time, this paper introduced a single-neuron control strategy, according to the nonlinear, load variety and condition uncertainty characteristics of the mechanical arm hydraulic drive system. It proved the feasibility and advantages of single- neuron PID control strategy in engineering mechanical arm hydraulic drive system control by the Modeling and Simulation of AMESim / Simulink. It provides a new control idea of simple, robust and intelligent for engineering mechanical arm hydraulic drive system.

This research was financially supported by the National Natural Science Foundation Project of China (Grant No. 51275060), the Young and Middle-aged Academic Leader Project of Jiangsu Province Cyanine Engineering of China (Grant No. SZ20130008).

\section{References}

[1] LIU Zhong, LIAO Yi-fan. High speed on-off valve pilot control hydraulic cylinder position control system modeling and Simulation Research of [J] Chinese mechanical engineering. 2006. 17(7):p.745 (In Chinese)

[2] YU Xiao, Liu Dong, LAN Weiyao. Parameter optimization of mechanical arm PID controller based on PSO algorithm [J] Modular machine tool and automatic processing technology, 2011, 2:p.89 (In Chinese)

[3] M.R.Sirouspour and S.E.Salcudean, Nonlinear Control of Hydraulic Robot, IEEE Transactions on Robotics and Automation, 2001, Vol.17 (2): 70-83.

[4] LU Ning, FU Yong-Ling, SUN Xin-xue. Application of single neuron in hydraulic system and Simulation of electro hydraulic [J], The Journal of system simulation, 2006,18(11):3180-3186. (In Chinese)

[5] Zhang M.G.,Li W.H.Single neuron PID model reference adaptive control based on RBF neural network. Proceedings of the 2006 International Conference on Machine Learning and Cybernetics . 2006 